\title{
Effect of aqueous extract of Achillea millefolium on the development of experimental autoimmune encephalomyelitis in C57BL/ 6 mice
}

\author{
Reza Vazirinejad, Fateme Ayoobi, Mohammad Kazemi Arababadi' ${ }^{1}$ Mohammad M. Eftekharian², \\ Ali Darekordi ${ }^{3}$, Mahdi Goudarzvand ${ }^{4}$, Gholamhossein Hassanshahi ${ }^{1}$, Mohammad Mohsen Taghavi ${ }^{5}$, \\ Behzad Nasiri Ahmadabadi, Derek Kennedy', Ali Shamsizadeh
}

Department of Physiology, PhysiologyPharmacology Research Center, Rafsanjan University of Medical Sciences, Rafsanjan, Iran, ${ }^{1}$ Immunology of Infectious Diseases Research Center,

${ }^{5}$ Department of Anatomy, Faculty of Medicine, Rafsanjan University of Medical Sciences, Rafsanjan, ${ }^{2}$ Molecular Medicine Research Center, Faculty of Para Medicine, Hamadan University of Medical Sciences, Hamadan, ${ }^{3}$ Department of Chemistry, Faculty of Science, Vali-e-Asr University of Rafsanjan, Rafsanjan, ${ }^{4}$ Department of Physiology and Pharmacology, Faculty of Medicine, Alborz University of Medical Sciences, Karaj, Iran, ${ }^{6}$ School of Biomolecular and Physical Science, Eskitis Institute for Cell and Molecular Therapies, Griffith University Nathan, Queensland, Australia

Received: 10-06-2013

Revised: 28-08-2013

Accepted: 20-03-2014

Correspondence to:

Dr. Ali Shamsizadeh,

E-mail: ashamsi@rums.ac.ir, alishamsy@gmail.com

\section{ABSTRACT}

Objective: Achillea millefolium (A. millefolium) is widely used as an anti-inflammatory remedy in traditional and herbal medicine. In this study, we investigated the effect of an aqueous extract from A. millefolium on experimental autoimmune encephalomyelitis (EAE) and on the serum cytokine levels in C57BL/ 6 mice.

Materials and Methods: EAE was induced in 63 C57BL/6 mice weighing 20-25 g (8 weeks old). Following immunization, the treatment protocol was initiated by using different doses of an aqueous extract from A. millefolium (1, 5, and $10 \mathrm{mg} /$ mouse/day). Histopathologic assessments were performed by hematoxylin and eosin ( $\mathrm{H}$ and $\mathrm{E}$ ) and luxol fast blue (LFB) staining. Behavioral disabilities were recorded by a camera. Serum levels of interleukin (IL)-10, IL-12, and transforming growth factor (TGF)- $\beta$ were measured using enzyme-linked immunosorbent assay (ELISA).

Results: On average, mice developed classical behavioral disabilities of EAE, $13.2 \pm 1.9$ days following immunization. Treatment of mice with A. millefolium led to delay the appearance of behavioral disabilities along with reduced severity of the behavioral disabilities. Treatment with A. millefolium prevented weight loss and increased serum levels of TGF- $\beta$ in immunized mice with MOG35-55. EAE-induced mice, which were treated with A. millefolium, had less cerebral infiltration of inflammatory cells.

Conclusion: The results demonstrated that treatment with aqueous extract of A. millefolium may attenuate disease severity, inflammatory responses, and demyelinating lesions in EAE-induced mice. In addition, following treatment with A. millefolium, serum levels of TGF-ßwere increased in EAE-induced mice.

KEYWORDS: Achillea millefolium, cytokines, experimental autoimmune encephalomyelitis, multiple sclerosis

\section{Introduction}

Multiple Sclerosis (MS) is a complex disorder and despite years of focused research, the main etiological factors for

\begin{tabular}{|l|l|}
\hline \multicolumn{2}{|c|}{ Access this article online } \\
\hline Website: www.ijp-online.com & Quick Response Code: \\
\hline DOl: 10.4103/0253-7613.132168 & \\
&
\end{tabular}

pathological processes are yet to be identified. ${ }^{[1]}$ Experimental autoimmune encephalomyelitis (EAE) has been used as a model for MS in animals worldwide ${ }^{[2]}$ and has assisted in the identification of autoantigens associated with its pathology and progression. It is now well-documented that inflammatory responses may have a role in pathogenesis of EAE. ${ }^{[3]}$ A broad range of different proinflammatory mediators including cytokines such as tumor necrosis factor (TNF)- $\alpha$, interleukin (IL)-6, IL-1 $\beta$, interferon (INF)- $\gamma$, and IL-17, enzymes like cyclooxgenase-2, transcription factors, nuclear factor kappa $\mathrm{B}(\mathrm{NF}-\kappa \mathrm{B})$ and CCAAT-enhancer binding protein-B $(\mathrm{C} / \mathrm{EBB})$ are believed to be involved in activation of cytotoxic T lymphocytes, 
macrophage, and glial cells, which are responsible for the proinflammatory response in EAE. ${ }^{[3]}$ Proinflammatory responses results in destruction of oligodendrocytes. ${ }^{[4]}$

Achillea millefolium (A. millefolium) or yarrow, a flowering plant from the family of Asteraceae, is widespread and frequently used as a medicinal plant worldwide. ${ }^{[5]} \mathrm{A}$. millefolium has been used as a treatment for several disorders varying from wound healing, infectious diseases, pain, and gastrointestinal complaints to many other conditions. ${ }^{[6]}$ Although A. millefolium has been suggested as a folk remedy for the traditional treatment of central nervous system diseases, few data have been published supporting this claim. Elmann et al., reported that $A$. millefolium extract has anti-inflammatory effects on lipopolysaccharide (LPS)-activated primary cultures of brain microglial cells. ${ }^{[7]}$ Therefore, they concluded that $A$. millefolium could be beneficial in preventing or treating neurodegenerative diseases like Alzheimer and Parkinson's disease. In another study, Molina-Hernandez et al., reported anticonflict-like actions of aqueous extract of the flowers of $A$. millefolium in rats. ${ }^{[8]}$ Also recently, Baretta et al., reported that acute and chronic oral administration of hydroalcoholic extract of $A$. millefolium exerted anxiolytic-like effects in mice. ${ }^{[9]}$

Hence, the aim of this study was to investigate the effects of aqueous extract of $A$. millefolium, on the development of $\mathrm{EAE}$ in $\mathrm{C} 57 \mathrm{BL} / 6$ mice.

\section{Materials and Methods}

\section{Animals}

Adult (8-12 weeks old) male C57BL/6 mice were purchased from the Pasteur Institute (Tehran, Iran) and were used for EAE induction. Mice were kept under optimal conditions based on the temperature, hygiene, humidity, and light (cycles of $12 \mathrm{~h}$ dark/light). They had free access to food and water. The method of this study was approved by local ethics committee (Ethics and Animal Care Committee of Rafsanjan University of Medical Sciences) and all experiments were conducted according to the standard ethics guidelines.

\section{Reagents}

Myelin oligodendrocytes glycoprotein (MOG) was purchased from Alexis Company, USA. Complete Freund's adjuvant (CFA), cresyl fast violet, pertussis toxin, luxol fast blue (LFB), and lithium carbonate were purchased from Sigma-Aldrich, USA.

\section{Preparing of Plant Materials}

The plant material was collected during March 2011 from Isfahan Botany Herbarium and was identified by Dr Valiollah Mozaffarian at Botany Research Division, Research Institute of Forests and Rangelands, Tehran, Iran. A voucher specimen has been kept in Isfahan Botany Herbarium voucher specimen no. 9757. The dried aerial parts of the plant (200 g) were rinsed with distilled water, dried, ground into powder and extracted in a Soxhlet apparatus with distilled water. The solvent was evaporated under reduced pressure at $40^{\circ} \mathrm{C}$. The resultant extract was then reconstituted by solving it in distilled water before being used in animals. Three of more common doses of extract were selected to use in this study $(40,200$, and $400 \mathrm{mg} / \mathrm{kg}){ }^{[6,10,11]}$ Due to the fact that the most of mice weighed around $24 \mathrm{~g}$, we converted the mentioned doses per mouse $(1,5$, and $10 \mathrm{mg} / \mathrm{mouse})$.

\section{Experimental Groups}

In this study, mice were randomly allocated into seven equal groups (seven mice per group) as follows: (1) Control group; no intervention was performed in this group, (2) EAE group; EAE was induced in this group using MOG35-55, CFA, and pertussis toxin, (3) Sham group; animals received CFA and pertussis toxin without MOG, (4-6): In these three groups, animals were initially subjected to EAE induction followed $24 \mathrm{~h}$ later by 1, 5, and $10 \mathrm{mg} / \mathrm{mouse} /$ day $A$. millefolium for 21 days, and 7: The healthy mice received $10 \mathrm{mg} / \mathrm{mouse} /$ day $A$. millefolium for 21 days. The last group was designed to study any effect of A. millefolium on overall health of the rats (see Table 1 for the treatment regime).

\section{Induction of EAE in Mice}

EAE was induced using a peptide corresponding to the sequence of the rodent myelin oligodendrocytes glycoprotein MOG35-55. Experimental mice received a subcutaneous injection of $250 \mu \mathrm{g}$ MOG35-55/mouse emulsified in CFA containing $0.4 \mathrm{mg}$ Mycobacterium tuberculosis. Animals also received $500 \mathrm{ng} /$ mouse pertussis toxins immediately after immunization and $48 \mathrm{~h}$ later. In sham-treated group, animals received CFA and pertussis toxin, but did not receive MOG. Mice were monitored daily for weight loss and neurological signs of EAE. The severity of disease among EAE mice were scored (6 grades) based on the method reported by Onuki et al., as follows: Grade $0=$ if there was no sign of disease, grade $1=$ if there was partial loss of tail tonicity, grade $2=$ if there was loss of tail tonicity along with tail righting disabilities, grade 3 = if there was unsteady gait and mild paralysis of one hind limb, grade $4=$ if there were both hind-limb paralysis and incontinence, grade $5=$ if there was quadriplegia, and grade $6=$ death. $^{[12]}$ The mice were humanely sacrificed 21 days after immunization with MOG35-55.

\section{Histological and Microscopic Assessments}

On the $21^{\text {st }}$ day of EAE induction, animals were anesthetized with injection of high dose of thiopental. Blood samples were collected before intracardiac perfusion of animals with phosphate buffered saline (PBS; pH 7.4) containing 4\% (w/v) paraformaldehyde solution. The whole brain was dissected out from each animal and the dissected tissues were fixed

Table 1:

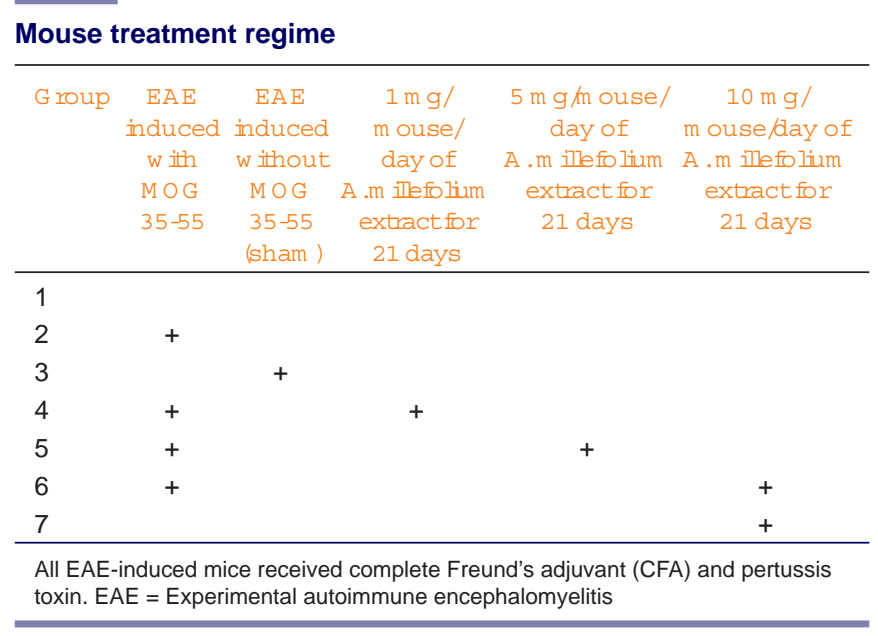


and divided into two hemispheres: The right hemisphere was used for histological staining, ${ }^{[13]}$ whereas, the left hemisphere was used for myelin staining. For histological analysis, routine histology methods were carried out to obtain morphological details of the brain tissue in EAE mice. Paraformaldehyde fixed tissues were embedded in paraffin, and serial sections $(8 \mu \mathrm{m})$ were prepared. Sections were stained with a conventional hematoxylin and eosin (H and E) staining method. Digital images were taken using a $\times 40$ objective. Slides were assessed in a blinded fashion for inflammation by trained experts from the Department of Anatomy, Rafsanjan University of Medical Sciences. Inflammation was scored using the following scale: $0=$ No infiltrating cells were observed; $1=$ few infiltrating cells were seen; 2 = numerous infiltrating cells were visible; and 3 = widespread infiltration was observed. Six serial sections of right hemisphere of each mouse in each group were scored. The processes of counting were performed in similar sections and in similar microscopic fields in all groups. Sections of the left hemisphere were incubated in $0.1 \%$ LFB dissolved in $95 \%$ ethanol and $0.05 \%$ acetic acid at $60^{\circ} \mathrm{C}$ for $18 \mathrm{~h}$. Stained sections were differentiated in $0.05 \%$ lithium carbonate and $70 \%$ ethanol. Sections were then counterstained with cresyl fast violet, dehydrated, and mounted with enthalen. ${ }^{[14]}$ Six sections of left hemisphere of each mouse were stained with LFB and were checked for demyelinating plaque.

\section{Determination of Immunologic Factors}

The serum levels of IL-10, transforming growth factor (TGF)- $\beta$, and IL-12 were measured using enzyme-linked immunosorbent assay (ELISA; eBioscience, ESP). Briefly, the monoclonal antibodies against IL-10, TGF- $\beta$, and IL-12 were precoated in polyester ELISA plates and $24 \mathrm{~h}$ after incubation and washing were blocked in the PBS buffer containing 3\% bovine serum albumin for $2 \mathrm{~h}$. Samples were then added to the well plates and were incubated for $2 \mathrm{~h}$. The plates were washed again and biotin-conjugated antibodies against the cytokines were added to the plates and were again incubated for $2 \mathrm{~h}$. After washing the plates, horseradish peroxidase (HRP)-avidin was added and further incubated for another $30 \mathrm{~min}$. Finally, the plates were washed, substrate (TMB $+\mathrm{H}_{2} \mathrm{O}_{2}$ ) was added and after 15 min of incubation the reaction was stopped by addition of $2 \mathrm{~N} \mathrm{H}_{2} \mathrm{SO}_{4}$. The absorption was measured using an ELISA plate reader. The sensitivity of kits was $2 \mathrm{pg} / \mathrm{ml}$ and inter- and intra-assay assessments of reliability of the kits were evaluated and produced scores of CV $<14 \%$ and $<0.03 \%$, respectively.

Data Analysis

Data were analyzed using excel and Statistical Package for Social Sciences (SPSS). All data were reported as a mean \pm standard error of mean (SEM) and a $P$ value less than 0.05 was considered as a significant difference. Differences between the groups were measured using one-way analysis of variance (ANOVA) followed by the Dunnett's post hoc test. Repeated measure ANOVA (RMA) was also used to compare weight changes in the days subsequent to induction of EAE.

\section{Results}

\section{Behavioral Scores}

In Group 2 (the EAE group), the first behavioral scores of EAE emerged following $13.2 \pm 1.9$ days of immunization. In this group, the behavioral scores increased to peak level of $3.4 \pm 0.8$ by 17 days following immunization (RMA, $P=0.049$ ). Treatment with $A$. millefolium delayed the onset of behavioral changes compared to EAE group. In Groups 4 and 6 (received 1 and $10 \mathrm{mg} /$ mouse of $A$. millefolium, respectively), behavioral scores of EAE were observed from 18 and 17 days after immunization, respectively. In Group 5 (received $5 \mathrm{mg} /$ mouse of $A$. millefolium), we did not observe any behavioral score for EAE throughout the period of study [Figure 1]. The mean of behavioral score in Group $4(P=0.014)$ and Group $6(P=0.021)$ were significantly lower than Group 2 [Figure 1].

\section{Weight Changes}

The results showed that the mean weight of mice in Group 2 on the $21^{\text {st }}$ day were significantly lower than their mean weight on the $1^{\text {st }}$ day after immunization with MOG $(P=0.003)$. The mean weight of mice in Groups 4-6 have not changed at $21^{\text {st }}$ day following immunization compared to the $1^{\text {st }}$ day of immunization in each group (all $P>0.3$ ) [Figure 2]. In Group 7 (only treated with $10 \mathrm{mg} / \mathrm{mouse} /$ day $A$. millefolium), we did not observe either behavioral disabilities or weight loss throughout the study, suggesting that the drug does not have a deleterious effect on general health.

\section{Histology}

$\mathrm{H}$ and $\mathrm{E}$ staining on the coronal sections of cerebrum in Group 2 showed massive infiltration of inflammatory cells into the brain tissue [Figure 3a]. In contrast, in groups 4-6 the infiltration of inflammatory cells into the brain tissue was decreased [Figure 3a]. The number of inflammatory cells decreased in Group $5(P=0.013)$ and $6(P=0.010)$ compared to group 2 [Figure 3b].

Coronal sections of left cerebrum were stained with LFB. Demyelinating lesions were more evident in Group 2 [Figure 4]. In Groups 4-6 lesser demyelinated lesions in the brain were observed [Figure 4]. However, we did not perform statistical analysis for the number of lesion areas in the experimental groups.

Figure 1: Mean of behavioral scores of mice in different groups. \#Means significant difference in the behavioral score between $E A E$ (measured at day 18) and EAE $+1 \mathrm{mg} /$ mouse Achillea millefolium (measured at day 20) $(P=0.014)$, *means significant difference in the behavioral score between EAE (measured at day 18) and $\mathrm{EAE}+10 \mathrm{mg} / \mathrm{mouse}$ A. millefolium (measured at day 20) $(P=0.021)$. $\mathrm{EAE}=$ Experimental autoimmune encephalomyelitis

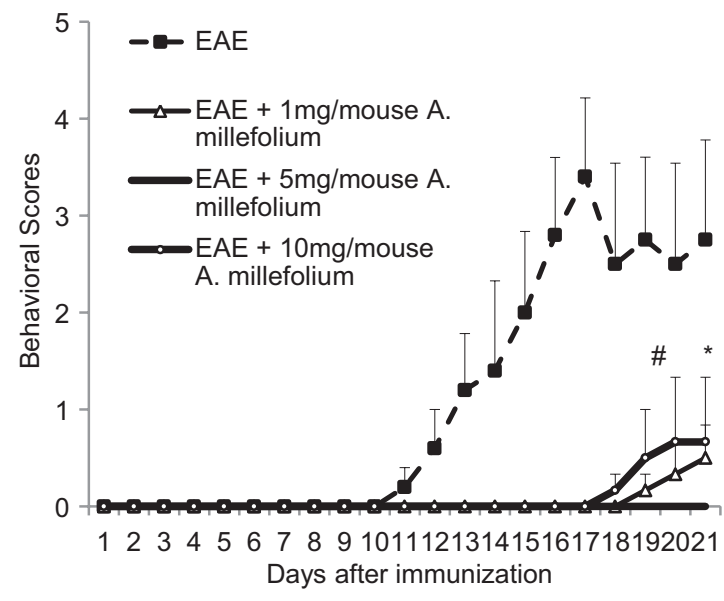


Figure 2: Mean of weight of mice in different groups. *Means significant difference between day 1 and 21 in EAE group $(P=0.003)$

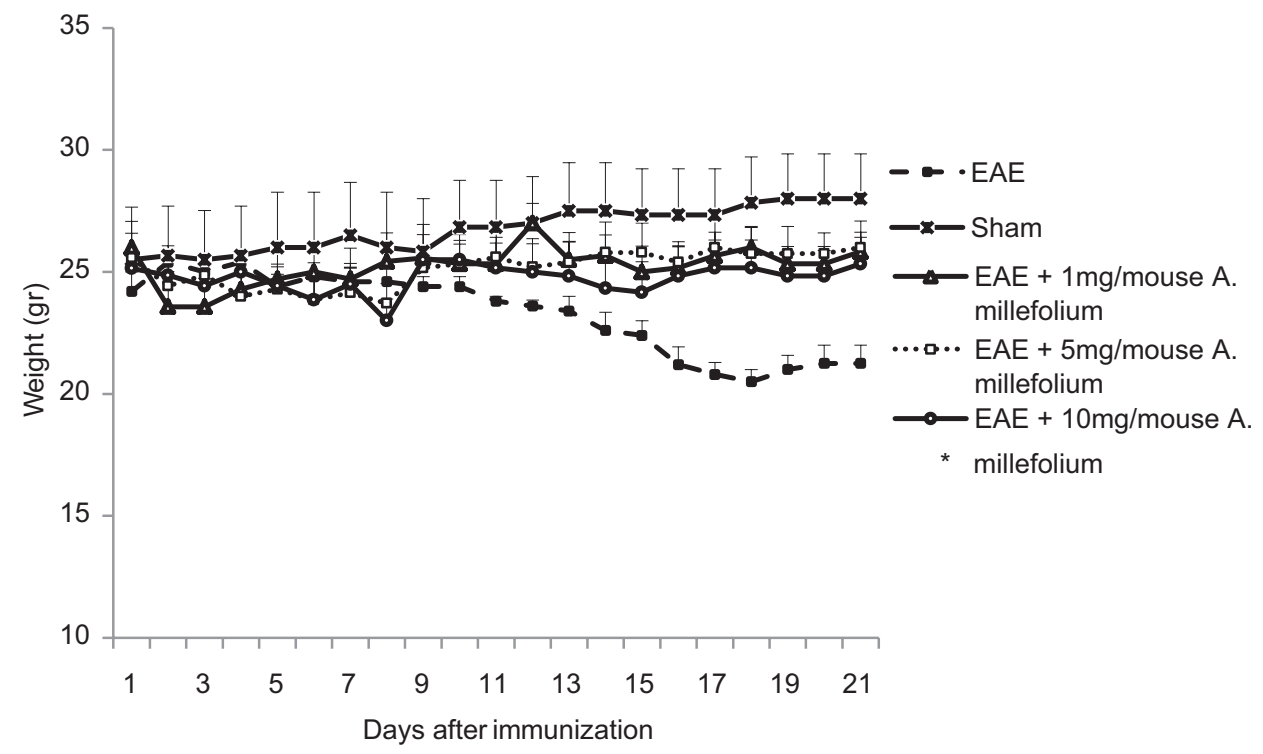

Figure 3: $\mathrm{H}$ and $\mathrm{E}$ staining on the coronal section of cerebrum in in EAE and EAE induced animals which treated by different doses of $A$. millefolium. Digital images were collected under a bright-field setting using a $\times 40$ objective. (a) A1 is for sham, A2 = EAE, A3 = EAE+1 mg/ mouse $A$. millefolium, $A 4=E A E+5 \mathrm{mg} /$ mouse $A$. millefolium and $A 5=$ $\mathrm{EAE}+10 \mathrm{mg} / \mathrm{mouse} \mathrm{A}$. millefolium groups. Arrows show inflammatory infiltrates. (b) Shows the inflammation index (see methods) in different groups. "significant difference between EAE and EAE $+5 \mathrm{mg} / \mathrm{mouse}$ A. millefolium $(p=0.013)$. "significant difference between $E A E$ and EAE $+10 \mathrm{mg} /$ mouse A. millefolium $(P=0.01)$

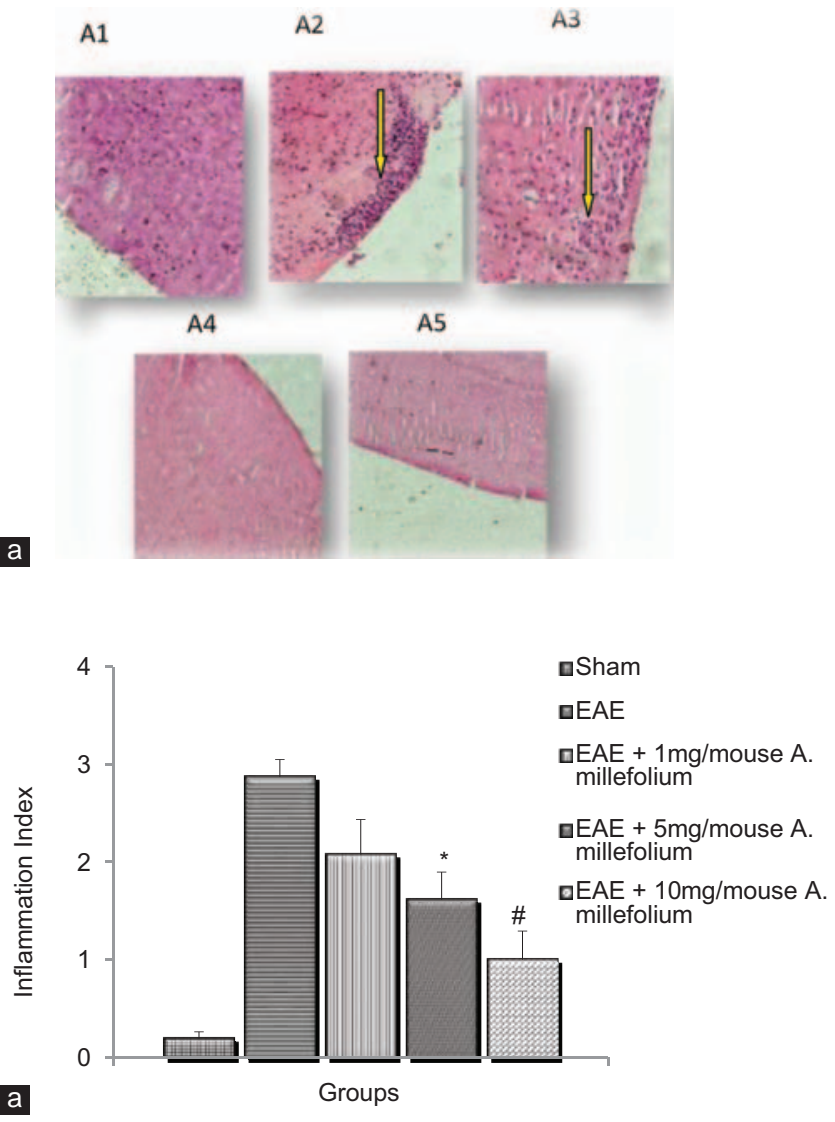

Figure 4: Luxol fast blue staining on the coronal section of cerebrum in different groups. Digital images were collected under a bright-field setting using a $\times 40$ objective. $a$ is for sham, $b=E A E, c=E A E+1$ $\mathrm{mg} /$ mouse $A$. millefolium, $\mathrm{d}=\mathrm{EAE}+5 \mathrm{mg} / \mathrm{mouse} A$. millefolium, and $\mathrm{e}=\mathrm{EAE}+10 \mathrm{mg} / \mathrm{mouse} A$. millefolium groups. Arrow points towards demyelination area in $B$ group

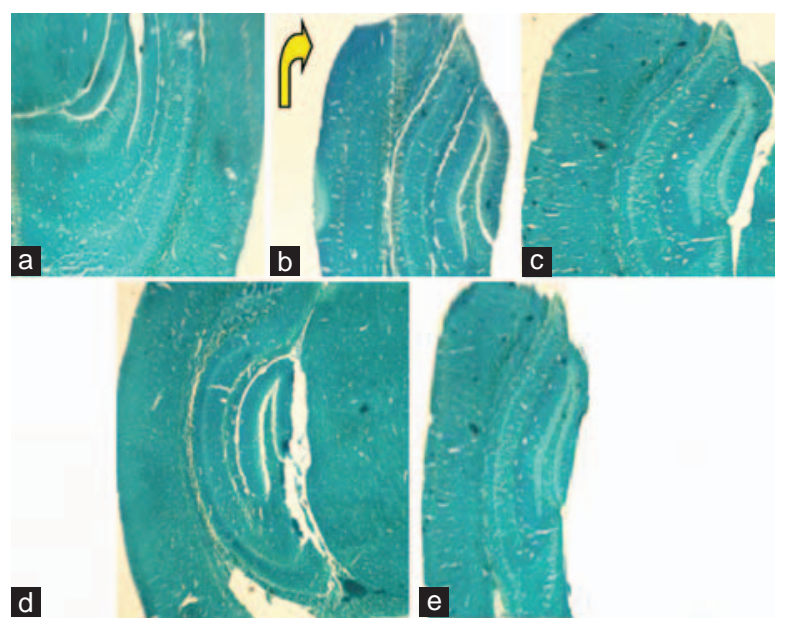

Serum levels of $I L-10, I L-12$, and $T G F-\beta$

Our results showed that mean serum levels of IL-10 and IL-12 were not significantly different between the experimental groups. Serum levels of TGF- $\beta$ was higher in Groups 4-6, compared with Group 2, however, the difference was significant only in Group $6(P=0.026)$ [Table 2].

\section{Discussion}

The results demonstrate that treatment of EAE mice model with aqueous extract of $A$. millefolium inhibited the development of EAE symptoms and complications (both behavioral presentations and inflammation). Our results also revealed that the serum levels of IL-10 and IL-12 were not significantly altered in different experimental groups, however, the circulating TGF- $\beta$ levels were significantly increased in the EAE-induced mice 
Table 2:

Mean serum levels of IL-10, IL-12, and TGF- $\beta$ in different groups

\begin{tabular}{|c|c|c|c|}
\hline \multirow[t]{2}{*}{ Groups } & \multicolumn{3}{|c|}{ M ean $\pm S D$ (m in $-m$ ax) } \\
\hline & $\mathbb{I}-10$ & $\mathbb{L}-12$ & $T G F=\beta$ \\
\hline EAE & $333.3 \pm 218.7(173-705)$ & $48.2 \pm 43.5(14-106)$ & $1,228.4 \pm 1,061.7(5-2,267)$ \\
\hline Sham & $448.2 \pm 325.7(136-978)$ & $20.1 \pm 4.8(13-24)$ & $2,184.6 \pm 546.8(1,426-2,822)$ \\
\hline 10 mg/mouse Achillea millefolium & $1,209.3 \pm 970.5(126-2,452)$ & $33.8 \pm 28.7(12-76)$ & $2,537.2 \pm 549.5(1,886-3,091)$ \\
\hline $\mathrm{EAE}+1 \mathrm{mg} / \mathrm{mouse}$ A. millefolium & $939.2 \pm 491.3(386-1,619)$ & $27.2 \pm 19.0(12-63)$ & $2,361.0 \pm 872.3(1,475-3,634)$ \\
\hline $\mathrm{EAE}+5 \mathrm{mg} /$ mouse $A$. millefolium & $1,469.6 \pm 2,214.7(100-5,384)$ & $121.6 \pm 181.2(18-438)$ & $2,317.7 \pm 296.7(1,897-2,593)$ \\
\hline $\mathrm{EAE}+10 \mathrm{mg} /$ mouse $A$. millefolium & $273.9 \pm 129.7(136-451)$ & $22.5 \pm 12.1(14-46)$ & $2,736.5 \pm 663.0(1,640-3,615)^{\star}$ \\
\hline
\end{tabular}

Data are presented as mean \pm SD. *Means significant difference between EAE and EAE $+10 \mathrm{mg} A$. millefolium in TGF- $\beta(P=0.026)$. EAE $=$ Experimental autoimmune encephalomyelitis, IL = Interleukin, TGF = Transforming growth factor, SD = Standard deviation

treated with $10 \mathrm{mg} /$ mouse of $A$. millefolium suggesting that the effects of the extract on TGF- $\beta$ may be dose-dependent, but this would need to be assessed in further research programs.

The anti-inflammatory effects of $A$. millefolium have been documented in earlier studies. ${ }^{[6]}$ It has been demonstrated that one of the main consequences of EAE and MS, is the infiltration of activated $\mathrm{T}$ cells and associated mononuclear cells such as macrophages into the central nervous system (CNS). This in turn is facilitated by a broad-spectrum of inflammatory consequences. Therefore, according to previous reports we investigated whether treatment with $A$. millefolium could attenuate the infiltration of $A$. millefolium inflammatory cells in EAE mice. Our results demonstrated that $A$. millefolium decreased the infiltration of inflammatory cells into the cerebrum of EAE treated animals. Consistent with our results, there are several reports regarding the anti-inflammatory properties of $A$. millefolium. Benedek et al., in 2007 have reported that $A$. millefolium inhibits inflammation related proteases, including human neutrophil elastase (HNE) and matrix metalloproteinases (MMPs) in vitro. ${ }^{[15]}$ In another report, Maswadeh et al., showed that a gel containing $6 \% \mathrm{~A}$. millefolium extract reduced paw edema (approximately 50\%) in rats. ${ }^{[16]}$ The inhibitory effects of $A$. millefolium on some mediators of inflammation such as MMPs may play an important role in the preventative effects of this extract on EAE, this is confirmed by some studies that report both MMP 2 and 9 were increased in MS. ${ }^{[17,18]}$ It has also been reported that oxidative stress influences the severity of MS. ${ }^{[19]}$ Furthermore, there are reports demonstrating the antioxidant properties of $A$. millefolium. ${ }^{20]}$ Konyalioglu and Karamenderes, screened 15 different species of Achillea for their antioxidant activities by using several in vitro assays on human erythrocytes and leukocytes. ${ }^{[20]}$ Therefore, it is interesting to speculate that one of the possible mechanisms by which $A$. millefolium inhibits development of EAE could occur through its antioxidative properties. However, further investigations are required to shed light on this.

With regards to the fact that TGF- $\beta$ contributes to the processes of matrix synthesis, ${ }^{[21]}$ it may be reasonable to conclude that $A$. millefolium may induce the remyelination of injured neurons via upregulation of TGF- $\beta$ in the EAE model. Interestingly, it has been shown that TGF- $\beta$ induces the expression of chemotactic factors from microglia which are specific for the recruitment of oligodendrocyte precursor cells (OPC) in C57BL/6 mice. ${ }^{\mid 22]}$ OPCs chemoattraction to the demyelinating CNS lesions is one of the main determining factors for remyelination. ${ }^{|22|}$ Moreover, there is compelling data demonstrating that TGF- $\beta$ has anti-inflammatory effects on the immune cells (such as NK cells and T cytotoxic lymphocytes). ${ }^{23]}$ Hence, itseems that treatment with A. millefolium maydownregulate inflammation in EAE at least partially via induction of TGF- $\beta$. On the other hand, TGF-b play dual roles when it is associated with other cytokines, ${ }^{[24]}$ therefore, future studies should be directed at looking a wider range of inflammatory cytokines (such as IL-17, interferon gamma (IFN $\gamma$ ), IL-23, and IL-6) to evaluate the effects of $A$. millefolium on this system.

Overall, the results showed that the serum levels of IL-12 and IL-10 were not changed among the studied groups. It has been shown that IL-17A has antagonistic effect on the IL-12 and IL-10 secreting cells. Moreover, recent studies demonstrated that IL-17A is one of the main cytokines involved in the induction of the EAE, ${ }^{[25]}$ thus, it is difficult to reconcile the reported influence of IL-17A on EAE with our data that showed no changes in the downstream cytokines, IL-12 and IL-10. Further studies need to clarify possible interaction between these cytokines in EAE-induced mice.

To conclude $A$. millefolium can inhibit the development of EAE in mice. Future clinical studies on the effect of A. millefolium in patients with MS may be planned based on the findings of this study.

\section{Acknowledgments}

The authors acknowledge the Rafsanjan University of Medical Sciences and Physiology-Pharmacology Research Centre for the financial support for this study.

\section{References}

1. DegenhardtA, Ramagopalan SV, ScalfariA, Ebers GC. Clinical prognostic factors in multiple sclerosis: A natural history review. Nat Rev Neurol 2009;5:672-82.

2. Costa O, Divoux D, Ischenko A, Tron F, Fontaine M. Optimization of an animal model of experimental autoimmune encephalomyelitis achieved with a multiple MOG (35-55) peptide in C57BL6/J strain of mice. J Autoimmun 2003;20:51-61.

3. Petermann $F$, Korn $T$. Cytokines and effector $T$ cell subsets causing autoimmune CNS disease. FEBS Lett 2011;585:3747-57.

4. Sakurai T. Roles of biologically active peptide in regulation of feeding behavior and energy homeostasis. Nippon Yakurigaku Zasshi 2003;122:236-42.

5. Candan F, Unlu M, Tepe B, Daferera D, Polissiou M, Sokmen A, et al. Antioxidant and antimicrobial activity of the essential oil and methanol extracts of Achillea millefolium subsp. millefolium Afan. (Asteraceae). J Ethnopharmacol 2003;87:215-20.

6. Applequist WL, Moerman DE. Yarrow (Achillea millefolium L.): A neglected panacea? A review of ethnobotany, bioactivity biomedical research. Econ Botany 2011;65:209-25 
7. Elmann A, Mordechay S, Erlank H, Telerman A, Rindner M, Ofir R. Anti-neuroinflammatory effects of the extract of Achillea fragrantissima. BMC Complement Altern Med 2011;11:98.

8. Molina-Hernandez M, Tellez-Alcantara NP, Diaz MA, Perez Garcia J, Olivera Lopez JI, Jaramillo MT. Anticonflict actions of aqueous extracts of flowers of Achillea millefolium L. vary according to the estrous cycle phases in Wistar rats. Phytother Res 2004;18:915-20.

9. Baretta IP, Felizardo RA, Bimbato VF, dos Santos MG, Kassuya CA, Gasparotto Junior A, et al. Anxiolytic-like effects of acute and chronic treatment with Achillea millefolium L. extract. J Ethnopharmacol 2012;140:46-54.

10. Goldberg AS, Mueller EC, Eigen E, Desalva SJ. Isolation of the antilinflammatory principles from Achillea millefolium (compositae). J Pharm Sci 1969;58:938-41.

11. Mascia Lopes FC, Benzatti FP, Mendonça Jordão Jr C, Duarte Moreira RR, Carlos IZ. Effect of the essential oil of Achillea millefolium $\mathrm{L}$. in the production of hydrogen peroxide and tumor necrosis factor- $\alpha$ in murine macrophages. Braz J Pharm Sci 2005:41:401-5.

12. Onuki M, Ayers MM, Bernard CC, Orian JM. Axonal degeneration is an early pathological feature in autoimmune-mediated demyelination in mice. Microsc Res Tech 2001;52:731-9.

13. Dasgupta S, Zhou Y, Jana M, Banik NL, Pahan K. Sodium phenylacetate inhibits adoptive transfer of experimental allergic encephalomyelitis in SJL/J mice at multiple steps. J Immunol 2003;170:3874-82.

14. DeBoy CA, Zhang J, Dike S, Shats I, Jones M, Reich DS, et al. High resolution diffusion tensor imaging of axonal damage in focal inflammatory and demyelinating lesions in rat spinal cord. Brain 2007;130:2199-210.

15. Benedek B, Kopp B, Melzig MF. Achillea millefolium L. s.I.-is the anti-inflammatory activity mediated by protease inhibition? J Ethnopharmacol 2007:113:312-7.

16. Maswadeh HM, Semreen MH, Naddaf AR. Anti-inflammatory activity of Achillea and Ruscus topical gel on carrageenan induced paw edema in rats. Acta Pol Pharm 2006;63:277-80.

17. Kandagaddala LD, Kang MJ, Chung BC, Patterson TA, Kwon OS. Expression and activation of matrix metalloproteinase-9 and NADPH oxidase in tissues and plasma of experimental autoimmune encephalomyelitis in mice. Exp Toxicol Pathol 2012;64:109-14.

18. Graesser D, Mahooti S, Madri JA. Distinct roles for matrix metalloproteinase-2 and alpha4 integrin in autoimmune $\mathrm{T}$ cell extravasation and residency in brain parenchyma during experimental autoimmune encephalomyelitis. J Neuroimmunol 2000;109:121-31.

19. Mossberg N, Movitz C, Hellstrand K, Bergstrom T, Nilsson S, Andersen O. Oxygen radical production in leukocytes and disease severity in multiple sclerosis. J Neuroimmunol 2009;213:131-4.

20. Konyalioglu S, Karamenderes. C. The protective effects of Achillea L. species native in Turkey against $\mathrm{H} 2 \mathrm{O} 2$-induced oxidative damage in human erythrocytes and leucocytes. J Ethnopharmacol 2005;102:221-7.

21. Zhong J, Hu N, Xiong X, Lei Q, Li L. A novel promising therapy for skin aging: Dermal multipotent stem cells against photoaged skin by activation of TGF-beta/ Smad and p38 MAPK signaling pathway. Med Hypotheses 2011;76:343-6.

22. Lalive PH, Paglinawan R, Biollaz G, Kappos EA, Leone DP, Malipiero U, et al. TGF-beta-treated microglia induce oligodendrocyte precursor cell chemotaxis through the HGF-c-Met pathway. Eur J Immunol 2005;35:727-37.

23. Parkinson JF, Mitrovic B, Merrill JE. The role of nitric oxide in multiple sclerosis J Mol Med (Berl) 1997;75:174-86

24. Zamarron BF, Chen W. Dual roles of immune cells and their factors in cancer development and progression. Int J Biol Sci 2011;7:651-8.

25. Pollinger B. IL-17 producing T cells in mouse models of multiple sclerosis and rheumatoid arthritis. J Mol Med (Berl) 2012;90:613-24.

Cite this article as: Vazirinejad R, Ayoobi F, Arababadi MK, Eftekharian MM, Darekordi A, Goudarzvand M, et al. Effect of aqueous extract of Achillea millefolium on the development of experimental autoimmune encephalomyelitis in C57BL/6 mice. Indian J Pharmacol 2014;46:303-8.

Source of Support: Nil. Conflict of Interest: No. 
Reproduced with permission of the copyright owner. Further reproduction prohibited without permission. 